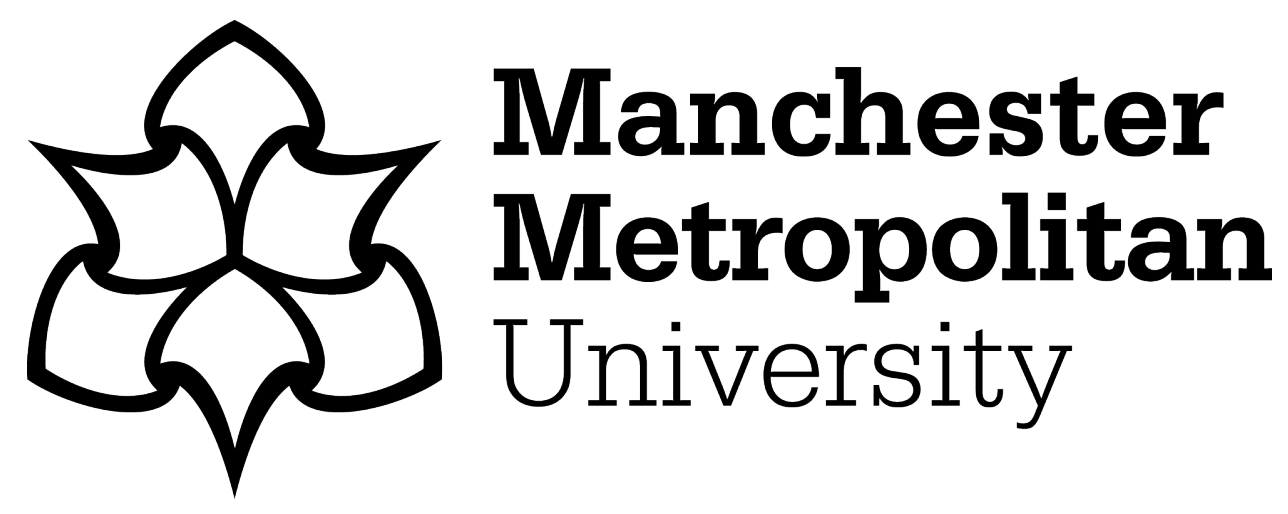

Grazzini, Laura, Donvito, Raffaele, Aiello, Gaetano, Pederzoli, Daniele, Godey, Bruno, Wiedmann, Klaus-Peter, Halliburton, Chris and Chan, PYL (2018) How Does Personality Congruence Help to Explain Luxury Brand Attachment? The Results of an International Research Study. In: 2018 Global Marketing Conference at Tokyo Proceedings, 26 July 2018 - 29 July 2018, Tokyo Japan.

Downloaded from: https://e-space.mmu.ac.uk/626165/

DOI: https://doi.org/10.15444/GMC2018.04.04.01

Please cite the published version 


\title{
HOW DOES PERSONALITY CONGRUENCE HELP TO EXPLAIN LUXURY BRAND ATTACHMENT? THE RESULTS OF AN INTERNATIONAL RESEARCH STUDY
}

Laura Grazzini, University of Florence, laura.grazzini@unifi.it

Raffaele Donvito, University of Florence, raffaele.donvito@unifi.it

Gaetano Aiello, University of Florence, gaetano.aiello@unifi.it

Daniele Pederzoli, NEOMA Business School, daniele.pederzoli@neoma-bs.fr

Bruno Godey, NEOMA Business School, bruno.godey@neoma-bs.fr

Klaus-Peter Wiedmann, Leibniz University of Hannover, wiedmannm2.uni-hannover.de

Chris Halliburton, ESCP Europe, challibu@escpeurope.eu

Priscilla Chan, Manchester Metropolitan University, p.chan@mmu.ac.uk

\begin{abstract}
The present study contributes to the international literature on brand personality and congruence. There is still a general lack of clarity regarding the measurement of the self-brand congruity construct. Moreover, in the light of international branding research cross-national validation of this measurement is needed. Previous empirical evidence also suggests a positive relationship between brand-self congruity and consumer-brand relationships (i.e. brand attachment) across nations and cultures, but the strength of these relationships requires deeper investigation. The present study therefore aims to test and validate a personality congruence scale at an international level and to measure the effect of congruence on brand attachment with specific reference to the luxury sector. A survey of nearly 1,500 international luxury customers has been conducted. Results confirm that personality congruence is based upon five dimensions (Prestige/Emotion/Trust/Anxiety/Order). In addition, the results highlight the existence and relative importance of the link between "personality congruence" and "brand attachment”. Finally, findings suggest similarities and differences across countries regarding specific dimensions of congruence scale and the personality congruence and attachment relationship. Both theoretical and managerial implications are provided.
\end{abstract}

Keywords: Brand personality, store personality, consumer personality, personality congruence, luxury. 